\title{
Handoff Priority Schemes in Wireless Mobile Cellular System
}

S. A. Mawjoud

Electrical Eng. Dept.

University of Mosul

\author{
H. A. Al-Tayyar
}

\section{Abstract}

Handoff operation, algorithm and modeling is vital in wireless cellular system. Two fundamental handoff procedures exist. The first model concerning the propagation environment and the second model is the limited channel resources which is dealt with in this paper. A realistic model of guard channel priority representing mobility is suggested and simulated.

Keywords: Wireless network, Handoff priority schemes.

$$
\begin{aligned}
& \text { أولوبتطرق المنافة لقلم لساكي خلوي متلى }
\end{aligned}
$$

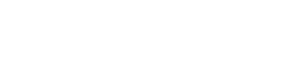

$$
\begin{aligned}
& \text { سالي عبد الموجود } \\
& \text { غنم الهنسة الكهربائية } \\
& \text { المستخلص }
\end{aligned}
$$

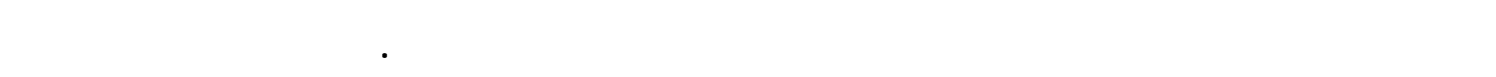

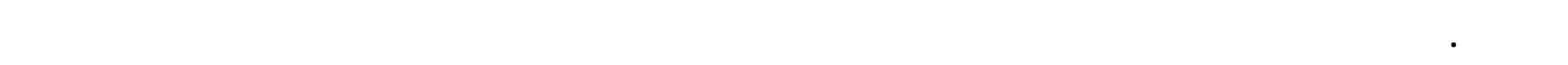

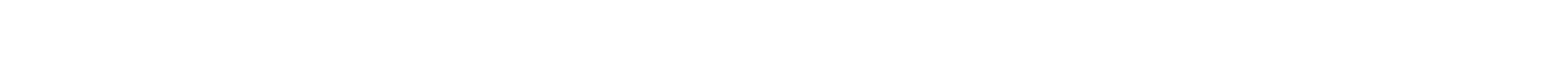
الولعية في الخلايا ومن ثم محكالة هذا الموذج ورلمالسة خوالصه. 


\section{Introduction:}

For efficient wireless mobile network, the handoff procedure of mobile stations moving from one cell to another cell in the intended coverage area is of prime importance. The number of handoff should be minimum (i.e. necessary handoff). Unnecessary handoff (or wrong cell handoff) results in worsening the performance of the network especially new calls blocking probabilities or a sudden call termination when a call is in progress.

Since studying the variations of system parameters is not feasible practically, simulation is a vital tool to study the performance by investigating the effect of various system parameters variations represent the real system environments.

- Hard handoff is applicable in GSM system, as shown in figure 1. It is called break before make i.e. the mobile station (MS) is disconnected from the serving base station (BS1) before connection with neighboring base station (BS2) i.e. the MS is connected to one base station at a time [1][2].

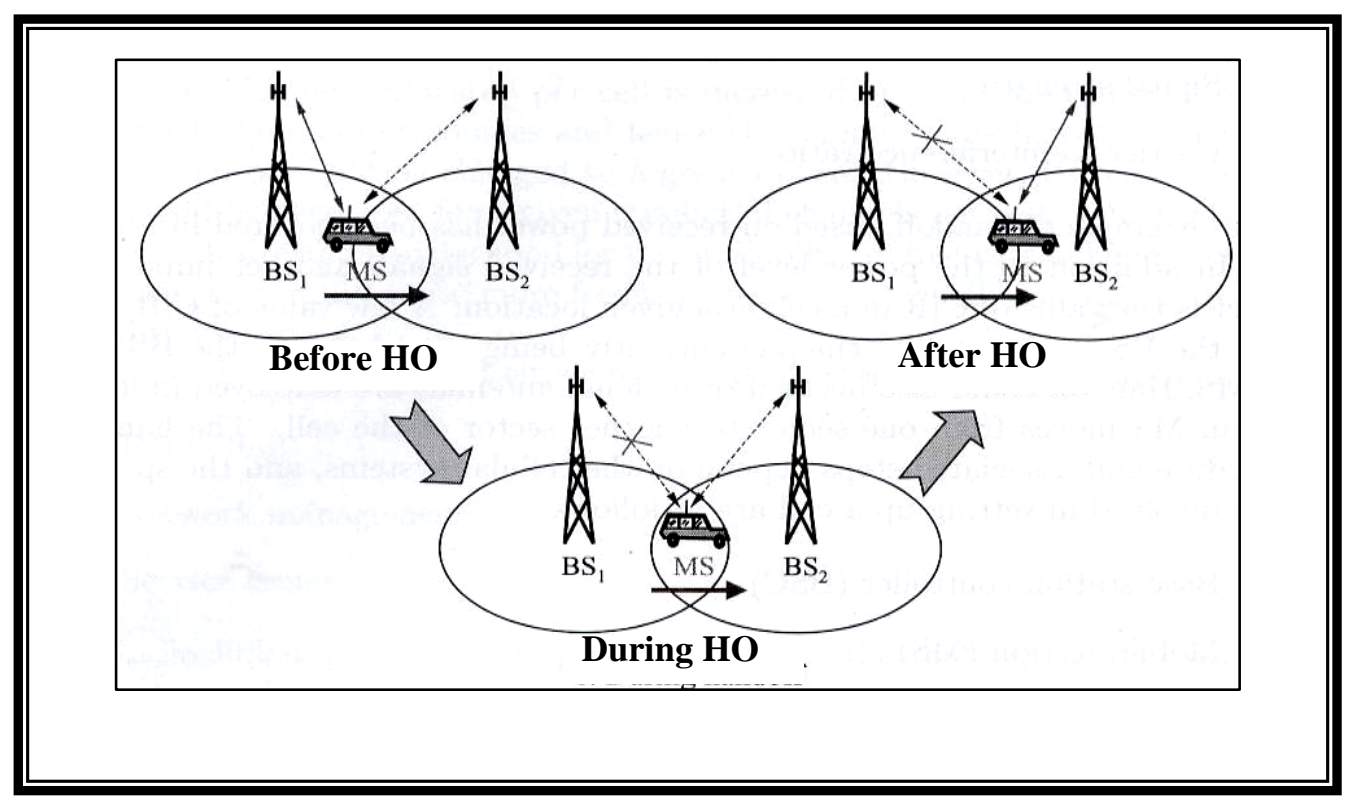

Fig. 1 Hard handoff (HHO) [2]

\section{Methods of Handoff Priority:}

Handoff operation is vital in system performance especially new calls blocking probability and sudden call termination (handoff failure).

To illustrate the different handoff priority in a one way traffic (either voice traffic or data traffic), a cellular system can be assumed to be consisting of many cells each has $\mathrm{S}$ number of channels, call service rate $(\mu)$, average call arrival rate $\lambda_{N}$ and average handoff calls $\lambda_{\mathrm{H}}[1][2]$.

\section{- Non-Priority Handoff Scheme:}

In this method, new calls and handoff calls are shared in all channels (S) available in the cell. The base station (BS) controls the management of handoff calls the same way it controls new calls and both are blocked with the same probability as in figure 2 . 


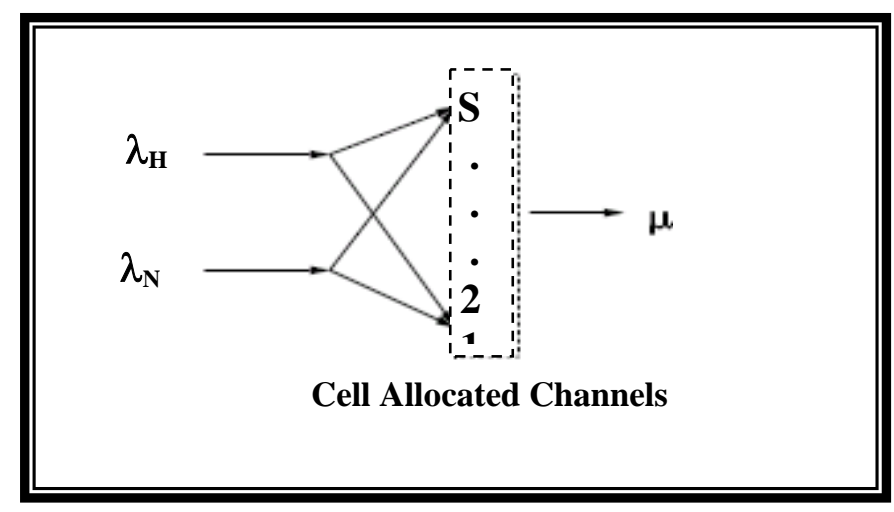

Fig. 2 Model of HO method with non-priority [1]

\section{- Priority Handoff Scheme:}

From the users point of view call termination during connection is more annoying than initiating a new call, therefore handoff's for continuing calls are given priority to new calls initiation[3].

Efficient priority schemes which provide high optimization of wireless bandwidth by adaptation with high number of new initiated calls. Whilst insuring quality of service (QoS) for handoff calls[4].

\section{- Guard Channel Priority (GCP):}

In this method, priority is given for handoff requests by allocating a number of channels $\left(S_{R}\right)$ for handoff requests only and the remaining channels $\left(S_{c}=S-S_{R}\right)$ are shared by handoff calls and new call initiation. New calls request are blocked if the number of available channels is less or equals to $S_{R}$. Handoff request is blocked if there is no available (vacant) channel in the cell [1][5]. Figure 3 illustrates GCP. The allocations of a group of channels for handoff will only reduce the general traffic channels, so the network capacity is reduced in addition to not completely utilization the radio spectrum [4]. The efficient utilization for GCP requires more accurate knowledge of the number of reserved channels and the knowledge

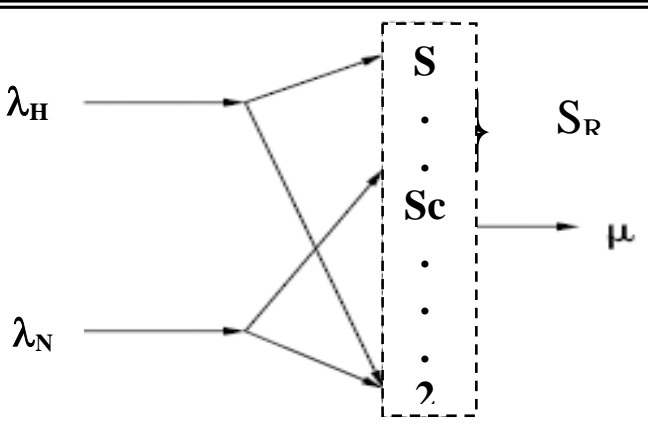

Cell Allocated Channels

Fig. 3 Model of handoff with guard channel priority [4] of traffic in the intended area.

To evaluate the performance in guard channel priority scheme, the important parameters used are [6]:

- Blocking probability.

- Handoff failure probability. 


\section{Limited Channel Resources:}

Each cell has limited capacity (S channels), theses channels are shared between new calls and HO calls. In case priority is given to handoff calls the BS does not differentiate the new calls from handoff calls; but when priority is given for handoff, the new calls established in the cell that has not empty channels will not be completed, but handoff calls are given priority. The most important priority methods is the guard channel priority (GCP).

The GCP simulation model is designed, and a number of channels are reserved for handoff calls only to reduce handoff failure [2][6][7].

Before going into details in the GCP simulation model, the factor affecting this model are, cell capacity (number of available channels in the cell) and the reserved channels for handoff.

\subsection{Cell Capacity:}

The handoff of a call is defined by two important random factors [2]:

a- The average number of MSs requesting the service which is the average number of call arrival rate $(\lambda)$ where:

$$
\lambda=\frac{\text { Number of Requests }}{\text { Time }}
$$

b- The average time the MS requests to service (average holding time $(\mathrm{H})$ ).

The traffic load $(\alpha)$ is given by:

$$
\alpha=\lambda \mathrm{H}
$$

where the unit of $\alpha$ is Erlang.

For example: Suppose a cell in which the average number of MSs is approximately 100. If the call request during one hour is 30 and average time of MS service H equals 360 sec, then the average call request is:

$$
\lambda=\frac{30 \text { Call }}{3600 \mathrm{sec} \text {. }}
$$

and the traffic load $\alpha$ is:

$$
\begin{aligned}
\alpha & =\frac{30 \text { Calls }}{3600 \mathrm{sec} .} \times 360 \mathrm{sec} . \\
& =3 \text { Erlang }
\end{aligned}
$$

Assuming call requests is Poisson distribution [2] then the blocking probability B is given by:

$$
B(S, \alpha)=\frac{\alpha^{S} / S i}{\sum_{K=0}^{S} \frac{\alpha^{K}}{K !}}
$$

Where $\mathrm{S}$ is the number of channels in the cell.

Equation 3 is called Erlang-B formula, and is given as:

$$
B(2,3)=\frac{\frac{3^{2}}{2 !}}{\sum_{K=0}^{2} \frac{3^{K}}{K !}}=0.6
$$


Therefore 0.6 of the calls will be blocked and need a new call initiation request and therefore the number of blocked calls is:

$30 \times 0.6=18$

\subsection{Simulation of Guard Channel Priority Model:}

The model designed consists of seven cells, a center cell and six neighboring cells as shown in figure 4.

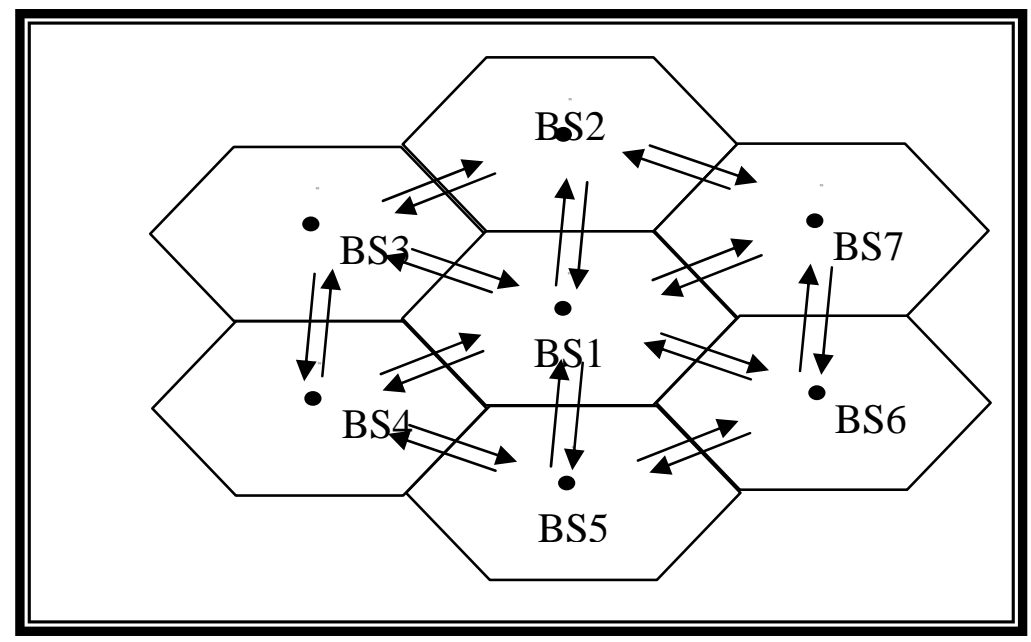

Fig. 4 Simulation model with guard channel nrioritv [8]

Assumptions used in the designed model are:

- Calls arrival rate is of Poisson distribution [8] of average call initiation time for MSs of 300 seconds.

- Holding time is exponential of average value of 180 seconds. According to exponential distribution, calls of longer holding time is of less probability of occurrence [9].

- The speeds of MSs are random and constant for every MS and of uniform distribution and a maximum MS speed of $60 \mathrm{~km} / \mathrm{hr}$

- The directions of MSs mobility's are between $0^{\circ}$ and $360^{\circ}$.

- The arrival of calls is memory-less including that each user (even the users whose calls are blocked) request channel at different times.

- There are limited channels available in the trunking pool, while the number of user's is unlimited. It is not important to know the number of MSs that is in the cell at a certain instant of time but the important is the actual number of synchronized calls in the cell [7].

Ten duplex channels are assumed in the cell $(S=10)$.

- The radius of the cell is $\mathrm{R}=1000 \mathrm{~m}$. 
- All the above assumptions apply equally to the cells in the proposed model.

The model proposed in figure 4 represent actual mobility of MSs from the central cell to the six neighboring cells and reverse mobility of MSs from the six neighboring cells to the central cell.

\section{Simulation Results:}

Figure 5 shows the handoff failure probability versus traffic intensity of each cell in Erlang for non-priority of handoff and for priority in handoff (for guard channels 1, 2 and 3).

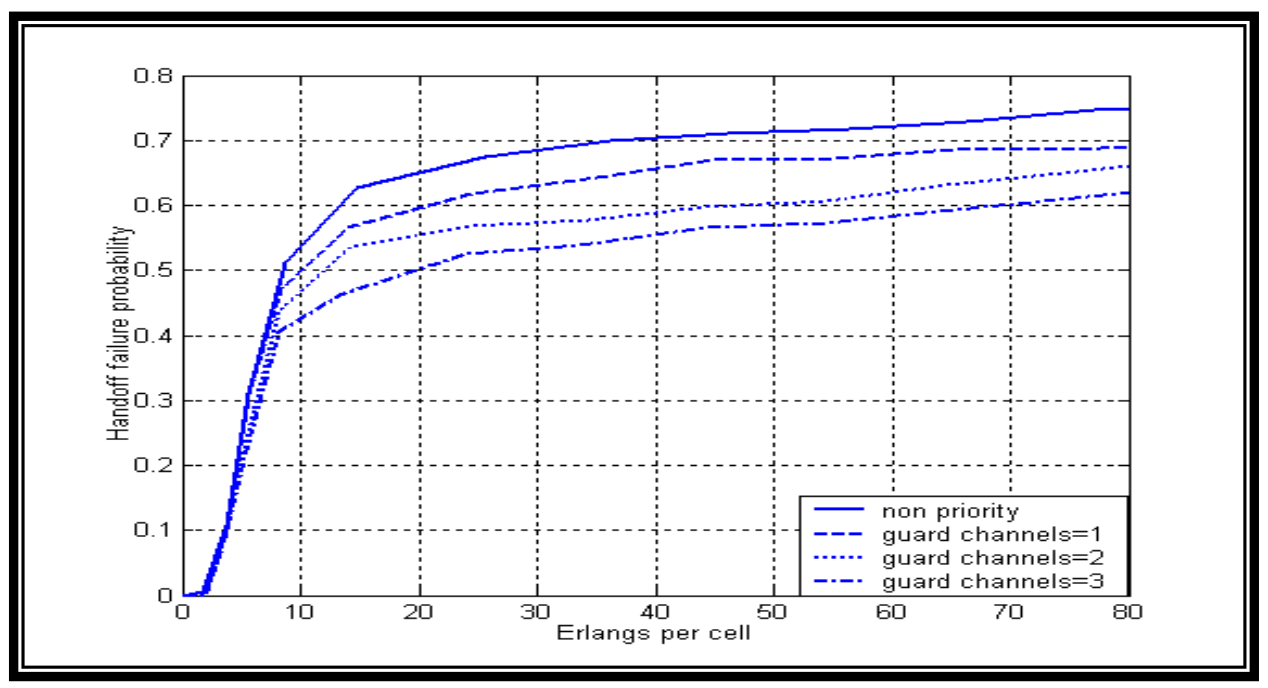

Fig. 5 Handoff failure probability versus traffic intensity in case of non-priority and priority

The non-priority, channels are not reserved for handoff and the channels are available for new calls and handoff calls, therefore the probability of handoff failure is high. In case of priority is given for handoff calls, the probability of handoff failure will be less due to reserved channels for handoff, and hence the probability of decreased handoff failure with increasing number of reserved channels.

Increased traffic load means increasing calls request and hence increased chances of handoff requests to the intended cell. As a result the probability of handoff failure increases since the number of channels in each cell is limited.

On the contrary of handoff failure probability there is the probability of blocking new calls which increases by giving priority to handoff and hence increases with increase in the number of channels reserved for handoff. The reason for that is the limited number of channels in the cell which are shared by new calls and handoff calls (i.e. increasing the service to one reduces the service to the other).

Figure 6 shows the new calls blocking probability versus traffic intensity. As in the case of increased in probability of handoff failure with increased traffic load, the new calls blocking probability increases with increased traffic load. 


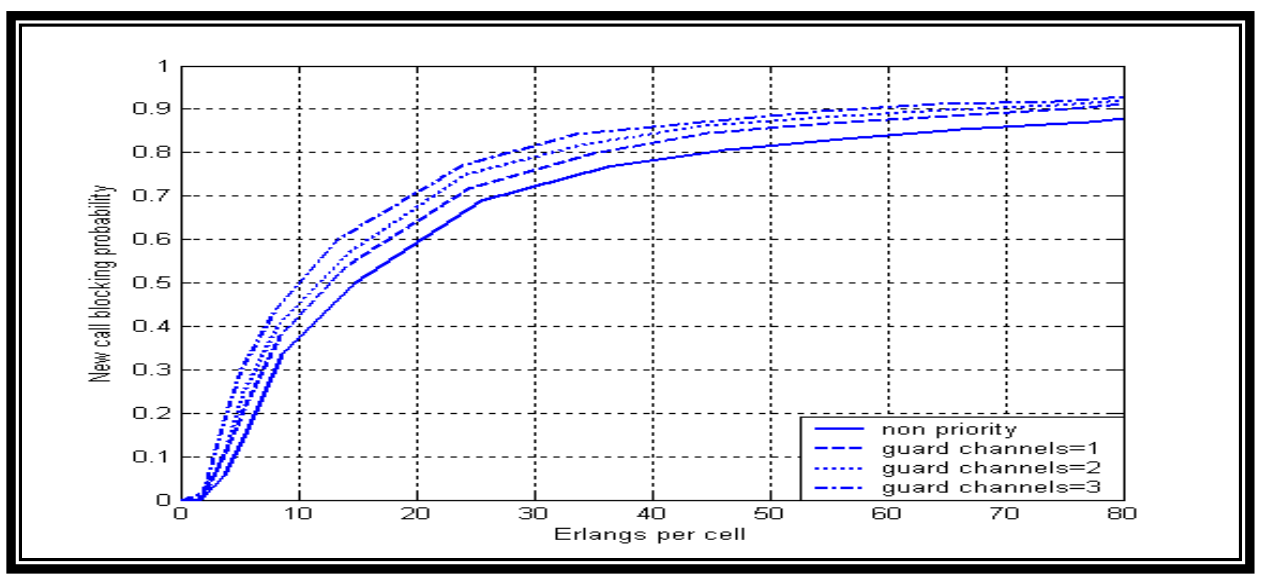

Fig. 6 New call blocking probability versus traffic intensity for non-priority and priority

\section{Conclusion:}

In the method of guard channel priority, it is noticed that the probability of handoff failure decrease as compared for the non-priority case. Since the BS does not distinguish handoff calls from new calls in case of not reserving channels for handoff's only, while in the GCP which reserve channels for handoff, the mobile distinguish between new calls and handoff calls by giving priority in providing channels for handoff's service.

\section{References:}

[1] D. P. Agrawal and Q. An-Zeng, " Handoff in Wireless Mobile Networks", John Wiley \& Sons, INC, 2002.

[2] D. P. Agrawal and Q. An-Zeng, "Introduction to Wireless and Mobile Systems", Thomson, Brooks/Cole, 2003.

[3] J. Hou, and Y. Fang, "Mobility-Based Call Admission Control Schemes fro Wireless Mobile Networks", Wirel. Commun. Mob. Comput., 2001.

[4] R. Sensharma, "Communication Networks Architecture", CDA, Fall 2002.

[5] N. Ekiz, T. Salih, S. Kucukoner and K. Fidaboylu, "An Overview of Handoff Techniques in Cellular Networks", International Journal of Information Technology, Vol. 2, No. 2, 2005.

[6] . Marichamy, S. Chakrabarti, and S. L. Maskara, "Overview of Handoff Schemes in Cellular Mobile Network and Their Comparative Performance Evaluation", IEEE Proc., Vehicular Technology Conference (VTC 99). Fall, Amsterdam, Sep. 1999.

[7] Maskara@ece.iitkgp.esnet.in, mascara @ gmail .com, maskara@,org._(Personal Communication).

[8] H. A. Al-Tayyar, "Study of Handoff Schemes in Cellular Systems", M. Sc. Thesis, Elect. Eng. Dept. University of Mosul, 2006.

[9] T. S. Rappaport, "Wireless Communication Principle and Practice", Prentice-Hall PTR, 2002.

The work was carried out at the college of Engg. 